\title{
The Steroid Growth-Requirement of Mycoplasma mycoides
}

\author{
BY A. W. RODWELL \\ Division of Animal Health, Animal Health Research Laboratory, C.S.I.R.O., \\ Parkville, N. 2, Victoria, Australia
}

(Received 4 December 1962)

\begin{abstract}
SUMMARY
Several steroids closely related structurally to cholesterol were tested for growth-promoting activity for a strain of Mycoplasma mycoides (V5) and a Mycoplasma sp. isolated from a goat (GY). Cholestanol and lathosterol promoted growth of both strains. Cholestenone, cholest-5-en-3-one, 7-dehydrocholesterol and progesterone inhibited cholesterol-promoted growth; cholestanone was almost inactive either as growth promotor or as growth inhibitor. Cholesterol amounted to $4-5 \%$ of the dry weight of the water-washed organisms, or about $20 \%$ of the total lipids, of either strain grown in the presence of cholesterol. Cholesterol esters or transformations to other steroids were not detected in lipid extracts of the v5 strain grown in the presence of cholesterol-4-14 $\mathrm{C}$. The GY strain was grown in the presence of cholesterol-4- ${ }^{-14} \mathrm{C}$ of known specific activity, the lipid extract diluted with a known amount of unlabelled cholesterol, and cholesterol isolated and purified. Its specific activity was very close to the value expected if no sterol transformations had occurred. When grown in the presence of cholestanol, the GY strain incorporated this sterol without desaturation.
\end{abstract}

\section{INTRODUCTION}

Certain species of the genus Mycoplasma differ from the Eubacteriales in possessing a steroid growth requirement. This requirement was first demonstrated by Edward \& Fitzgerald (1951), who found that cholesterol, cholestanol or stigmasterol were effective, and that the acetate, stearate or oleate esters of cholesterol were not. With some Mycoplasma strains of human and avian origin, it was shown by Smith $\&$ Lynn (1958) that $\beta$-sitosterol and cholestanol promoted better growth than did cholesterol, while ergosterol and stigmasterol were less effective. Cholesterol esters of saturated fatty acids of chain-length $\mathrm{C}_{4}-\mathrm{C}_{12}$ promoted growth less effectively than free cholesterol. These authors considered that the $3 \beta$-hydroxy group, either free or esterified, was essential. With Mycoplasma laidlawii, however, Butler \& Knight (1960) found that cholestanone, cholest-1-en-3-one and cholest-4-en-3-one all had nearly that same growth-promoting effect as cholesterol; cholesta-1,4-dien3-one and cholesta-1,4,6-trien-3-one inhibited completely the cholesterol-promoted growth of $\boldsymbol{M}$. laidlawii in a serum-free medium and of other Mycoplasma species in a medium which contained serum.

The lipid composition of several Mycoplasma strains, including two without a steroid requirement for growth, was examined by Lynn \& Smith (1960). They concluded that those strains which did not require steroid for growth did not contain any when grown in its absence. The steroid-requiring strains had a cholesterol 
content in free and esterified forms of from 0.7 to $0.9 \%$ of their dry weight. In one strain examined, there were esters of volatile and non-volatile fatty acids in about equimolar proportions; in another strain the esters were almost entirely those of volatile fatty acids. After sonic disintegration of the organisms, cholesterol was found in the insoluble and in the soluble fractions; the cholesterol esters were concentrated in the insoluble fraction, and the free cholesterol in the soluble fraction. Smith $(1959,1960)$ described both cholesterol ester-hydrolysing and ester-synthesizing activities in strains having a steroid growth requirement, and suggested that the function of these enzyme activities might be to mediate the transfer of volatile fatty acids across the membrane which encompasses the organisms.

Rothblat \& Smith (1961) examined the non-saponifiable lipid fraction. Nonfermentative steroid-requiring strains incorporated cholesterol unchanged or as an ester. With a fermentative steroid-requiring strain grown in the presence of glucose and cholesterol, about $80 \%$ of the incorporated steroid was in the form of the $\beta$-Dglucoside. Morowitz et al. (1962) found that the lipids of a strain of Mycoplasma gallisepticum contained about $6 \%$ cholesterol esters and $13 \%$ cholesterol.

Mycoplasma mycoides requires a steroid for growth (Edward \& Fitzgerald, 1951; Rodwell, 1956); a full study of this requirement has not yet been made. When viable particles were incubated in a medium deficient in cholesterol and a defatted serum protein fraction (Fraction $\mathbf{C}$ ), the viable count decreased rapidly. Loss of viability did not occur when another essential nutrient required for cytoplasmic synthesis (uracil) was also omitted, or when chloramphenicol was added. This suggested that a deficiency of lipid precursors caused a type of unbalanced growth in which there was impairment of the synthesis of the limiting membrane, but not of cytoplasm (Rodwell \& Abbot, 1961).

\section{METHODS}

Organisms. The strain v $\mathbf{5}$ of Mycoplasma mycoides of this laboratory was isolated from a case of bovine pleuropneumonia in 1936. Strain GY was isolated from a case of peritonitis in a goat (Laws, 1956). The GY strain, although incapable of causing pleuro-pneumonia in cattle, is related serologically and biochemically to $M$. mycoides Its nutritional requirements are like that of the $\mathbf{5}$ strain of $M$. mycoides (Rodwell, 1960).

Media. Medium B1 was as described for medium B by Rodwell \& Abbot (1961) except that the concentration of defatted bovine serum albumin (Fraction V) was decreased to $0.2 \mathrm{~g} . / \mathrm{l}$., and riboflavin added to the autoclaved medium as a sterile filtered solution. Riboflavin underwent partial destruction when autoclaved in this slightly alkaline medium. For medium B2, the concentrations of palmitate and oleate were doubled and that of defatted bovine serum albumin (Fraction V) increased to $0 \cdot 8 \mathrm{~g}$. $/ 1$. Steroids were added as aqueous dispersions in the concentrations indicated. Cholesterol-4 $4^{-14} \mathrm{C}$ was added as a fine stream of a solution in ethanol to the stirred medium at $60^{\circ}$ before the medium was autoclaved; the volume of solution used did not exceed $1 \%(\mathrm{v} / \mathrm{v})$.

Medium BVF-OS was as described by Turner, Campbell \& Dick (1935) but was supplemented with glycerol $(0.003 \mathrm{M})$, glucose $(0.02 \mathrm{M})$ and oleate $\left(2 \times 10^{-5} \mathrm{M}\right)$ and adjusted to $\mathrm{pH} 7 \cdot 9$ (Dr P. Plackett; personal communication). 
Growth tests. Duplicate tubes containing $5 \mathrm{ml}$. amounts of medium were seeded with about $10^{7}$ viable particles suspended in $0 \cdot 1 \mathrm{ml}$. $0 \cdot 4 \mathrm{M}$-sucrose solution containing 0.01 M-phosphate buffer (pH 7.5). Growth was estimated turbidimetrically at $660 \mathrm{~m} \mu$ at intervals during static incubation at $37^{\circ}$. The optical density values recorded are in most instances after 24 and $65 \mathrm{hr}$. incubation for the $\mathrm{GY}$ and $\mathrm{v} 5$ strains, respectively, when the turbidities were approaching the maximum values.

Steroids. The following steroids were prepared. (i) Cholesterol dibromide (Fieser, 1953). (ii) Cholesterol; m.p. $149 \cdot 3-150^{\circ} ; \alpha_{D}=-39 \cdot 5^{\circ}, c=1.0$ in $\mathrm{CHCl}_{3}$, by reduction of $(i)$ in accordance with Fieser (1953). (iii) $5 \alpha, 6 \beta$-dibromocholestane-3one, by chromic acid oxidation of $(i)$ (Fieser, 1953). (iv) Cholest-5-en-3-one, m.p. 118-121 $1^{\circ}$, by reduction of (iii) (Fieser, 1953). (v) Cholest-4-en-3-one (cholestenone) m.p. $79 \cdot 5^{\circ}-80 \cdot 5^{\circ}$, by isomerization of $(i v)$ with oxalic acid (Fieser, 1953). (vi) Cholestane-3-one (cholestanone) m.p. $129 \cdot 7^{\circ}$, by chromic acid oxidation of cholestanol (Barton \& Cox, 1948). (vii) Cholesteryl palmitate (m.p. 77-79 ${ }^{\circ}$ ) by the method of Swell \& Treadwell (1955). (viii) Cholesteryl oleate, m.p. 42-45 ${ }^{\circ}$, by heating cholesterol with oleic acid (Page \& Rudy, 1930).

Other steroids were obtained from the California Corporation for Biochemical Research: cholestanol (m.p. 141.5-142.0 $0^{\circ}$, C Grade; cholest-7-en-3 $\beta$-ol (lathosterol, A Grade $\left(\alpha_{D}=+4 \cdot 25^{\circ}, c=2 \cdot 0\right.$ in $\mathrm{CHCl}_{3}$ at $\left.\left.19^{\circ}\right)\right)$; cholesta-5,7-dien-3 $\beta$-ol (7-dehydrocholesterol), B Grade (m.p. 143-144 ${ }^{\circ} ; \alpha_{D}=-116^{\circ}, c=1 \cdot 0$ in $\mathrm{CHCl}_{3}$ at 24. ${ }^{\circ}$ ); stigmasterol, C Grade (m.p. 162-166 ${ }^{\circ}$ ); ergosterol, C Grade (m.p. 145-155 ); progesterone, C Grade; cortisone, C Grade. The Radiochemical Centre, Amersham, Buckinghamshire, England, supplied cholesterol-4-14 $\mathrm{C}$ (specific activity $33 \cdot 8 \mu \mathrm{c}$./ $\mu$ mole).

Chemical procedures. Three methods were used for the extraction of steroids from the organisms. (i) The method of Folch, Lees \& Sloane-Stanley (1957) which uses chloroform + methanol ( $2+1$ by vol.). (ii) Extraction of aqueous suspensions using about 25 vol. of acetone + ethanol $(1+1$ by vol.) mixture; the suspension was added to most of the solvent, the mixture brought to the boil, cooled, made to volume with solvent mixture, then filtered. (iii) Dry extraction of lyophilized material by refluxing with successive portions of ethanol + ether $(3+1$ by vol.) mixture.

The conditions for the saponification of extracts, digitonin precipitation and colorimetric estimation of cholesterol by the Liebermann-Burchard reaction were as described by Sperry \& Webb (1950). To conserve materials, the amounts of extracts and reagents were decreased so that the final reaction volume was $0 \cdot 45 \mathrm{ml}$. Optical densities were determined with a Beckmann model DU spectrophotometer equipped with a Lowry and Bessey attachment for $1 \mathrm{~cm}$. light-path microcuvettes. Total $3 \beta$-hydroxy sterol was determined by the anthrone method on the washed digitonide precipitates as described by Vahouny, Mayer, Roe \& Treadwell (1960).

Systems used for the paper chromatography of steroids were as follows. (i) System A (acetic acid + liquid paraffin B.P.) of Michalec \& Strasek (1960); (ii) System B (acetic acid + chloroform + liquid paraffin B.P. $80+15+5$ by vol.) of Michalec \& Strasek (1960); (iii) $n$-propanol + methanol + water $(15+8+3$ by vol.), saturated with liquid paraffin B.P. (Kodicek \& Ashby, 1954); (iv) acetic acid + water $(84+$ 16 by vol.) saturated with liquid paraffin B.P. (Peereboom, Copius \& Roos, 1960); (v) $n$-propanol + water $(60+40$ by vol.) saturated with kerosene (Martin \& Bush, 1955). The paper used for systems (i) to (iv) was Whatman No. 3 impregnated with 
liquid paraffin B.P., for system (v) it was Whatman No. 1 impregnated with kerosene. The solutions of steroids or of lipid extracts in chloroform were applied in a narrow band about $1 \mathrm{~cm}$. long at the origin of the papers. The papers for systems (i)-(iv) were irrigated by the ascending method for 3-6 hr. at room temperature, and for system $(\mathrm{v})$ by the descending method for $24 \mathrm{hr}$. at $37^{\circ}$. Steroids were located by spraying with an ethanolic solution of either phosphotungstic or phosphomolybdic acid (Martin, 1957).

Radioactive cholesterol was purified first by digitonin-precipitation followed by further purification through the dibromide derivative as described for amounts of the order of $1 \mathrm{mg}$. by Kabara \& McLaughlin (1961). The conditions for bromination were modified slightly, bromine being added as a solution in acetic acid and the reaction being allowed to proceed for $1 \mathrm{hr}$. at $30^{\circ}$.

Determination of radioactivity. A thin end-window Geiger counter was used. In some experiments, solutions of lipid extracts in ethanol were plated for counting on polythene planchets; in others, the solvent was ethanol + acetone $(1+1$ by vol.) mixture, and the solutions were then plated on aluminium planchets. In either case, a disc of lens tissue was used to obtain uniform distribution, and a drop of a $1 \%$ $(\mathrm{w} / \mathrm{v})$ aqueous solution of polyvinyl alcohol to attach the discs to the planchets. Samples were plated in duplicate at infinite thinness, except for the counts of radioactivity in the growth medium or in the supernatant fluid after growth. Selfabsorption corrections were applied for these, by counting a known amount of ${ }^{14} \mathrm{C}$ cholesterol added to the medium. When a more accurate count was desired, as in the determination of the specific activities, samples were plated in triplicate and corresponding replicate planchets counted in rotation. A count of a standard source was interposed between each set, and counting proceeded until a minimum of $\mathbf{5 0 0 0}$ counts was obtained from each sample.

\section{RESULTS}

\section{Effects of steroids on growth}

Cholesterol purified through the dibromide derivative had about the same growth-promoting activity for Mycoplasma mycoides strain $\mathrm{v} 5$ as had an unpurified sample. The growth responses of strain $v 5$ to cholesterol in media $\mathrm{B} 1$ and $\mathrm{B} 2$, and of strain GY in medium B2, are shown in Fig. 1. The concentration required for growth of the $\mathbf{5}$ strain was greater in medium B2 than in medium B1. Growth of the $v 5$ strain in either medium was abnormal in that the turbidity increased at an exponential rate until about half of the maximum value had been reached, and thereafter increased more slowly. The organisms were highly filamentous and remained so during continued incubation, particularly in medium B2. The GY strain grew in medium B2 with a doubling time of about $3 \mathrm{hr}$., and continued at about this rate until the turbidity approached the maximum value.

Tests were made of the growth-promoting activity of steroids in concentrations ranging from $2.5 \times 10^{-6} \mathrm{M}$ to $10^{-4} \mathrm{M}$, for strain $\mathrm{v} 5$ in medium $\mathrm{B} 1$ (Fig. $1 a$ ) and for strain GY in medium B2 (Fig. 1b). The only steroids which, for either strain, replaced cholesterol at all effectively were cholestanol and lathosterol. Dark-field examination with a light microscope revealed no differences in the morphology of the organisms when grown in the presence of these sterols or of cholesterol. The 
GY strain grew at a lesser rate with lathosterol than with cholesterol; with strain $\vee 5$, growth in medium B1 was inhibited by concentrations of lathosterol greater than $2 \times 10^{-5} \mathrm{M}$ (Fig. 1). 7-Dehydrocholesterol promoted no growth of strain $\mathrm{v} 5$, and slight growth of strain GY, cholestanone slight growth of both strains, cholestanone and cholest-5-en-3-one no growth of either strain. Stigmasterol and ergosterol promoted slight growth of strain v 5, progesterone and cortisone no growth. These last four steroids were not tested for growth of strain $\mathbf{G Y}$.
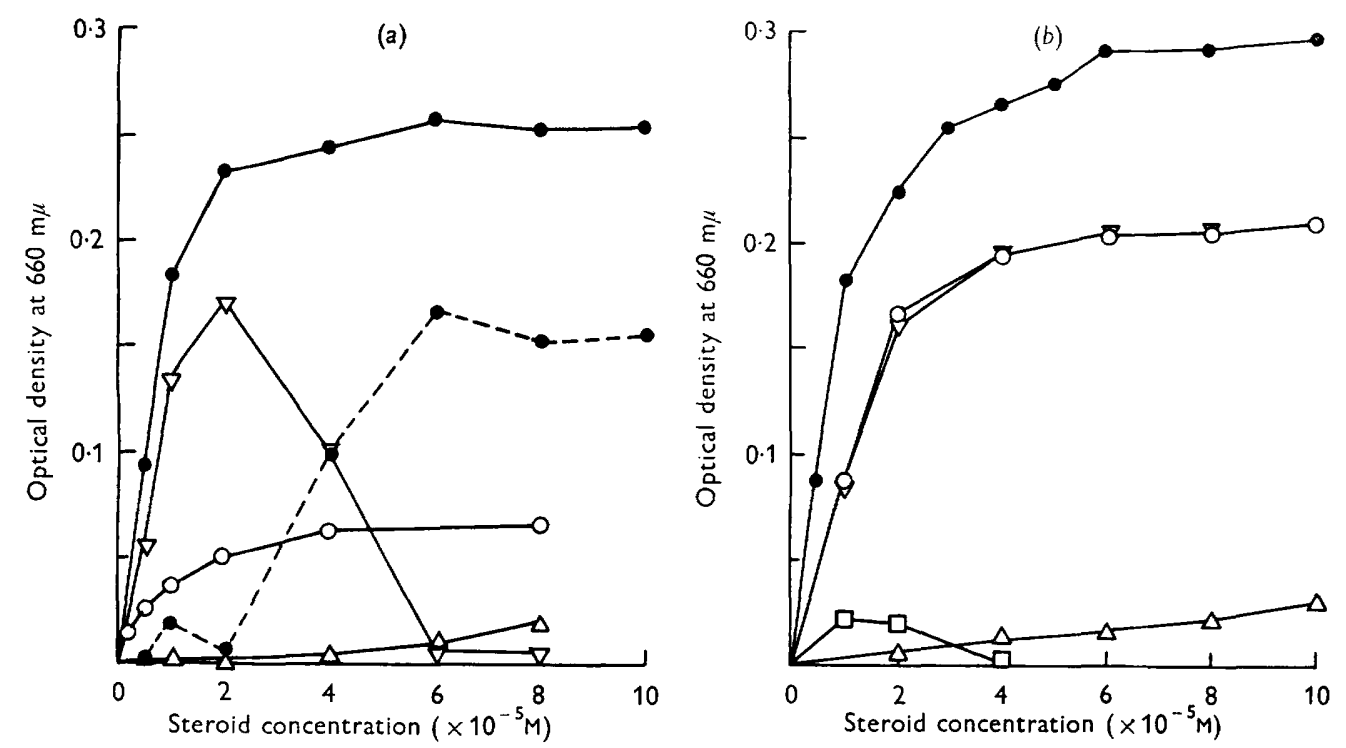

Fig. 1. Growth-promoting activity of steroids for Mycoplasma strains $\mathbf{v} 5$ and GY. (a) Strain v5; - medium B1; --- , medium B2. $65 \mathrm{hr}$. incubation.

(b) Strain GX; medium B2. , cholesterol; $\bigcirc$, cholestanol; $\triangle$, cholestanone; $\nabla$, lathosterol ;

$\square, 7$-dehydro-cholesterol $24 \mathrm{hr}$. incubation, except for lathosterol $40 \mathrm{hr}$. incubation.

The same steroids were tested for their effects on cholesterol-promoted growth of strains $\mathrm{V} 5$ and $\mathrm{GY}$ in media $\mathrm{B} 1$ and $\mathrm{B} 2$ containing $10^{-5} \mathrm{M}$ and $4 \times 10^{-5} \mathrm{M}$ cholesterol respectively. The results of some of these tests are illustrated in Fig. $2 a$ for strain v 5 and Fig. $2 b$ for strain Gy. Cholestenone and cholest-5-en-3-one (not included in Fig. 2) were about equally potent inhibitors of the cholesterol-promoted growth of both strains; 7-dehydrocholesterol was less potent. The effect of 7 -dehydrocholesterol was tested also on the growth of strain v 5 and medium B 1 containing $5 \times 10^{-5} \mathrm{M}$ cholesterol. The concentration $\left(\times 10^{-5} \mathrm{M}\right)$ resulting in a $50 \%$ decrease of growth increased from $0 \cdot 7$ for a cholesterol concentration of $10^{-5} \mathrm{M}$ to $2 \cdot 3$ for one of $5 \times 10^{-5} \mathrm{M}$. Cholestanone, lathosterol and cholestanol were either inactive, or caused only partial inhibition of growth at the highest concentration tested. Progesterone and cortisone inhibited growth of the $\mathrm{v} 5$ strain, the concentrations $\left(\times 10^{-5} \mathrm{M}\right)$ resulting in a $50 \%$ decrease being $\mathbf{2 \cdot 6}$ and $\mathbf{7 \cdot 2}$, respectively. Stigmasterol and ergosterol caused partial growth inhibition of strain $\mathrm{v} 5$ at the highest concentration tested $\left(8 \times 10^{-5} \mathrm{M}\right)$. These last four steroids were not tested for their effect on the cholesterolpromoted growth of strain $\mathrm{GY}$. 
The inhibitory concentrations of steroids for the GY strain were almost constant during the exponential growth phase, and increased when the incubation period was prolonged: e.g. the concentrations of cholestenone required for $50 \%$ decrease of growth of strain GY were 1.4 to $1.6 \times 10^{-5} \mathrm{M}$ for an incubation period of $16-24 \mathrm{hr}$. and $2 \cdot 7 \times 10^{-5} \mathrm{M}$ for one of $40 \mathrm{hr}$. The results illustrated in Fig. $2 b$ for strain $\mathrm{GY}$ are for an incubation period of $24 \mathrm{hr}$.
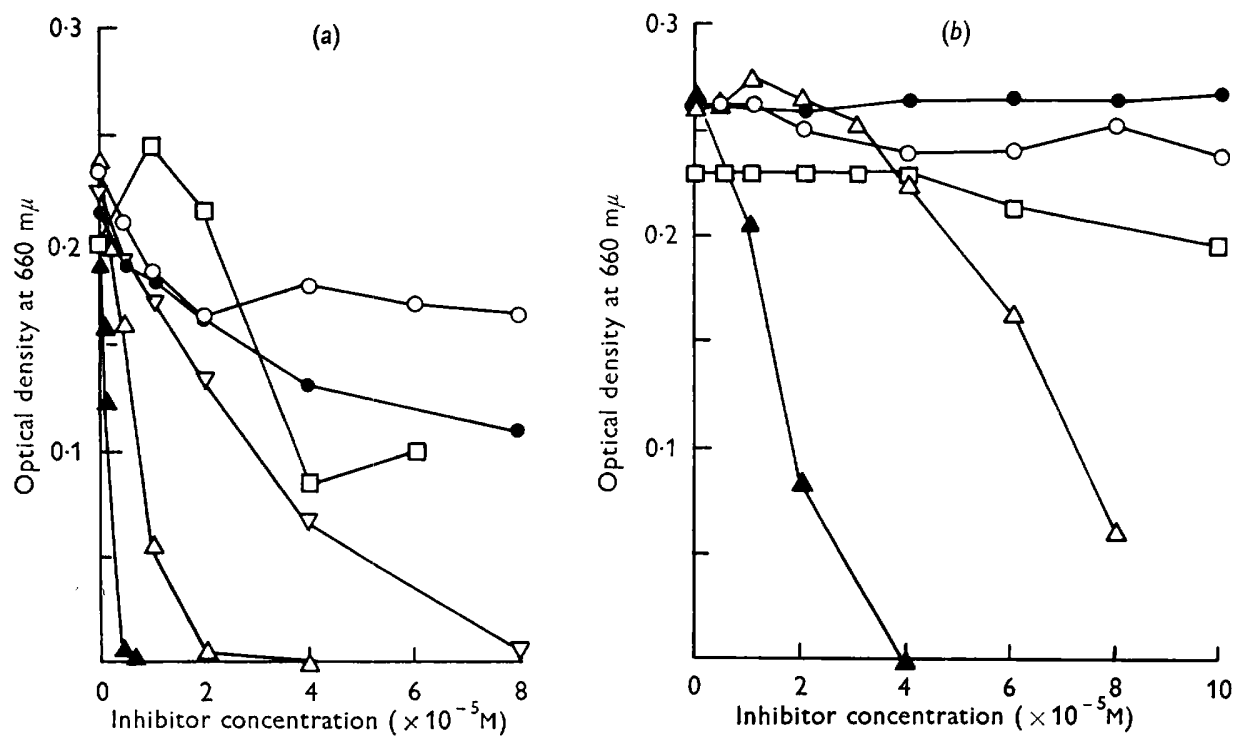

Fig. 2. Inhibition of cholesterol-promoted growth of Mycoplasma strains V5 and GY by steroids.

(a) Strain V 5 ; medium B1 cholesterol $10^{-5} \mathrm{M} .65 \mathrm{hr}$. incubation.

(b) Strain GY; medium B2 cholesterol $4 \times 10^{-5} \mathrm{M}$. 0 , cholestanol; $\square$, lathosterol;

$\triangle$, 7-dehydrocholesterol; $O$, cholestanone; $\Delta$, cholestenone; $\nabla$, progesterone. $24 \mathbf{~ h r}$. incubation.

\section{Steroid composition of organisms}

In a lipid extract (Folch method) of strain $\mathbf{} 5$ grown in supplemented BVF + OS medium, the digitonin-precipitable sterol was determined, directly and after saponification, by the Liebermann-Burchard reaction. Digitonin-precipitable sterol (estimated as cholesterol) represented $19 \%$ of the dry weight of the total lipid extract; the same value was obtained after saponification. It was therefore concluded that, if esters were present, their amount must have been small relative to the amount of free cholesterol. The same lipid extract was also examined for the presence of cholesterol esters by paper chromatography in systems (i) and (ii) (see Methods). When large amounts of extract were chromatographed, faint bands which migrated in the region of long-chain fatty acid esters were detected; these may have been derived from contamination by medium constituents. Esters were not detected in chromatograms of lipid extracts of strain $\mathbf{v} 5$ grown in medium $\mathrm{B} 1+$ cholesterol. The amount of Liebermann-Burchard positive material, estimated as cholesterol, was about $4 \%$ of the water-washed residue.

\section{Incorporation of ${ }^{14} \mathrm{C}$ labelled cholesterol}

The object of these experiments was to determine whether sterol esters had been formed in smaller amounts or whether steroid transformations had occurred. 


\section{Radioautography of paper chromatograms}

Organisms from $100 \mathrm{ml}$. culture of strain $\mathrm{v} 5$ in medium B 1 containing $2 \times 10^{-5} \mathrm{M}$ unlabelled cholesterol and $2 \mu \mathrm{c}$. cholesterol-4-14 $\mathrm{C}$ were harvested before maximum turbidity had been reached and while the culture still exhibited a pronounced 'swirl'. The organisms were washed with water, lyophilized and lipid extracts were prepared from the lyophilized residue as described in Table 1. The assessment of radioactivity in the fractions showed (Table 1 ) that $84 \%$ of the cholesterol supplied in the medium was incorporated, and that all of this was in lipid extract 1.

\section{Table 1. Incorporation of cholesterol-4-14 $\mathrm{C}$ by Mycoplasma strain $\mathbf{v} 5$}

The organisms from $100 \mathrm{ml}$. culture in medium B1 containing $2 \times 10^{-5} \mathrm{M}$ unlabelled cholesterol and $2 \mu \mathrm{c}$. cholesterol-4-14 $\mathrm{C}$ were washed twice with $15 \mathrm{ml}$. water and lyophilized (yield $7 \cdot 1 \mathrm{mg}$.). The lyophilized residue was thrice refluxed for $30 \mathrm{~min}$. with $2.5,1.0$ and $1.0 \mathrm{ml}$. ethanol + ether $(1+1)$ mixture and the extracts combined (lipid extract 1). This residue was then refluxed with $2 \mathrm{ml}$. ethanol + ether $(1+1)$ mixture for $1 \mathrm{hr}$. (lipid extract 2). The weight of the defatted residue was $5.6 \mathrm{mg}$.

$\begin{array}{lc}\text { Fraction } & \begin{array}{c}\text { Radioactivity } \\ \text { counts } / \text { min. } \\ \left(\times 10^{-3}\right)\end{array} \\ \text { Medium } & 156 \\ \text { Culture supernatant fluid } & 27 \\ \text { Water-washed residue } & 131 \\ \text { Lipid extract 1 } & 133 \\ \text { Lipid extract 2 } & 0 \cdot 2\end{array}$

Two ml. of lipid extract 1 were evaporated to dryness and dissolved in $50 \mu \mathrm{l}$. chloroform. Samples of this solution containing radioactivity equivalent to 3,300 counts $/ \mathrm{min}$. and $8 \cdot 4 \mu \mathrm{g}$. cholesterol (estimated colorimetrically) were chromatographed with a marker solution containing $10 \mu \mathrm{g}$. cholesterol and $16 \mu \mathrm{g}$. cholesterol palmitate in each of the five solvent systems described (see Methods). The marker solution alone and in admixture with a solution of ${ }^{14} \mathrm{C}$-labelled cholesterol containing radioactivity equivalent to 1450 counts $/ \mathrm{min}$. were included on each chromatogram. Radiograms were prepared from each of the chromatograms by exposure to $\mathrm{X}$-ray film for $\mathbf{5}$ and 21 days. The radiograms showed that the radioactive areas on all of the chromatograms coincided with the cholesterol areas. All five solvent systems separated cholesterol and cholesterol palmitate. Since radioactivity equivalent to about 25 counts $/ \mathrm{min} . / \mathrm{cm} .^{2}$ paper should be detectable after exposure for 3 weeks, it was concluded that $<1 \%$ of the cholesterol was esterified or transformed to other steroids separable in any of the solvent systems used. If no transformations had occurred, the cholesterol content calculated from the specific activity of the cholesterol supplied in the medium would be $4.2 \%$; the cholesterol content determined by the Liebermann-Burchard reaction was $4 \cdot 2 \%$.

\section{Isotope dilution}

Cholesterol-4-14 $\mathrm{C}$ was diluted with non-radioactive cholesterol and the mixture purified by the digitonin precipitation and dibromide procedure. The specific activity was 34.6 counts $/ \mathrm{min}$. $/ \mu \mathrm{g}$. cholesterol. Strain GY was grown in $100 \mathrm{ml}$. of 
medium $B$ to which purified radioactive cholesterol had been added to $5 \times 10^{-5} \mathbf{M}$. The organisms were harvested at the end of the exponential growth phase, washed with water, lyophilized, and a lipid extract was made from the lyophilized residue as described in Table 2 . The radioactivity determinations (Table 2) showed that $48 \%$ of the cholesterol had been incorporated. Only $90 \%$ of the radioactivity incorporated was recovered in the lipid extract; but, since very little remained in the residue after extraction, the discrepancy may be attributed to experimental error.

\title{
Table 2. ${ }^{14} \mathrm{C}$-cholesterol incorporation by Mycoplasma strain $\mathrm{GY}$
}

\begin{abstract}
Organisms from $100 \mathrm{ml}$. culture in medium $\mathrm{B2}$ containing $5 \times 10^{-5} \mathrm{M}^{-14} \mathrm{C}$-cholesterol (specific activity $34.6 \mathrm{count} / \mathrm{min}$. $/ \mu \mathrm{g}$. cholesterol) were washed once with $12 \mathrm{ml}$. water and lyophilized (yield $17.7 \mathrm{mg}$.). The lyophilized residue was refluxed with successive portions of ethanol + ether $(3+1)$ mixture and the extracts combined.
\end{abstract}

$\begin{array}{lc}\text { Fraction } & \begin{array}{c}\text { Radioactivity } \\ \text { counts } / \text { min. } \\ \left(\times 10^{-3}\right)\end{array} \\ \text { Medium } & \mathbf{6 1 \cdot 0} \\ \text { Culture supernatant fluid } & \mathbf{3 2 \cdot 4} \\ \text { Water-washed residue } & \mathbf{2 9 \cdot 0} \\ \text { Lipid extract } & \mathbf{2 6 \cdot 0} \\ \text { Defatted residue } & c .0 \cdot 2\end{array}$

An amount of the lipid extract which contained radioactivity equivalent to $17 \cdot 7 \times 10^{3}$ counts $/ \mathrm{min}$. (or $0.438 \mathrm{mg}$. cholesterol if the specific activity were unchanged) was diluted with $2.0 \mathrm{mg}$. purified non-radioactive cholesterol, and the cholesterol isolated from the mixture, as before. The specific activity of the isolated sample was $6 \cdot 1$ counts $/ \mathrm{min} / \mu \mathrm{g}$. cholesterol. If no sterol transformations had occurred, the specific activity after dilution would be expected to be $6 \cdot 2$ counts $/ \mathrm{min}$. $/ \mu \mathrm{g}$. cholesterol. The difference found is within the experimental error of the specific activity determinations. The experiment therefore did not detect any sterol transformations. The cholesterol content calculated from the specific activity of the cholesterol supplied and the amount of radioactivity incorporated was $4.7 \%$ of the water-washed residue.

\section{Cholestanol incorporation}

Strain GY was grown in $200 \mathrm{ml}$. medium B2 in which the cholesterol was replaced by cholestanol at $6 \times 10^{-5} \mathrm{M}$. The organisms were washed once with water and resuspended in $1 \mathrm{ml}$. water; the yield of water-washed organisms was $34.9 \mathrm{mg}$. Sterols were extracted from the aqueous suspension with ethanol+acetone $(1+1)$, and suitable samples of extract taken for precipitation of sterol digitonides. Total $3 \beta$-hydroxy sterols as determined by the anthrone method amounted to $4.8 \%$ of the water-washed organisms. Liebermann-Burchard positive sterols (as cholesterol) amounted to about $\mathbf{0 . 1} \%$ of the water-washed residue, but the colour obtained did not match that of the cholesterol standards, and was no doubt due largely, if not entirely, to interfering substances. It was concluded, therefore, that within the limits of detection cholestanol was incorporated without desaturation. 


\title{
Cholesterol exchange
}

The object of this experiment was to see whether cholesterol in the organisms exchanged with cholesterol in the medium during growth, and whether it could be displaced from the organisms by the growth-inhibitory steroid cholestenone. To replicate tubes of medium $\mathrm{B} 2$ were added: $(a)$ cholesterol $\left(4 \times 10^{-5} \mathrm{M}\right) ;(b)$ no steroid; (c) cholesterol + cholestenone $\left(4 \times 10^{-5} \mathrm{M}\right.$ each); $(d)$ cholestenone $\left(4 \times 10^{-5} \mathrm{M}\right)$. The tubes were inoculated with a suspension of organisms of strain GY which had been grown in a medium containing radioactive cholesterol (see Table 3). Immediately, and after $1,3,5.75 \mathrm{hr}$. incubation at $37^{\circ}$, one tube of each set was chilled, centrifuged and the radioactivity in the pellet was determined. Ater 5.75 incubation, the turbidity increased by factors of $2 \cdot 8$ and 1.7 in $(a)$ and $(b)$, respectively, but remained almost stationary in $(c)$ and decreased slightly in $(d)$. There was a loss of radioactivity from the sedimentable fraction, most of which occurred during the 1 st $\mathrm{hr}$. of incubation. The extent of this loss was similar under all conditions, about $75 \%$ of the radioactivity in the inoculum being present in the sedimentable fraction after $5.75 \mathrm{hr}$. incubation (Table 3 ). The reason for the loss of radioactivity from the organisms is not known; it might have been due to lysis of some of the organisms in the inoculum. Complete equilibration with cholesterol in the medium in $(a)$ would have decreased the radioactivity in the sedimentable fraction to $9 \%$ of that in the inoculum. It seems likely that cholesterol does not turn over during growth, and that once incorporated it cannot be displaced from the organisms by cholestenone.

\section{Table 3. Cholesterol exchange between the organisms of Mycoplasma strain $\mathrm{GY}$ and medium during incubation at $37^{\circ}$}

\begin{abstract}
Organisms for the inoculum were grown in $25 \mathrm{ml}$. medium $\mathrm{B2}$ containing $1 \mu \mathrm{c}$. cholesterol-4-14 $\mathrm{C}$ and $4 \times 10^{-5} \mathrm{M}$ nonradioactive cholesterol. Organisms were harvested while in the exponential growth phase, resuspended in $5 \mathrm{ml}$. sucrose + phosphate solution, and $0.25 \mathrm{ml}$. of suspension (containing radioactivity equivalent to $2 \cdot 3 \times 10^{3}$ counts $/ \mathrm{min}$.) was used to inoculate replicate tubes containing $4.75 \mathrm{ml}$. of medium $\mathrm{B} 2$ with steroid additions as indicated. After incubation at $37^{\circ}$ for the periods indicated, tubes were chilled, centrifuged, and the radioactivity in the pellets determined.
\end{abstract}

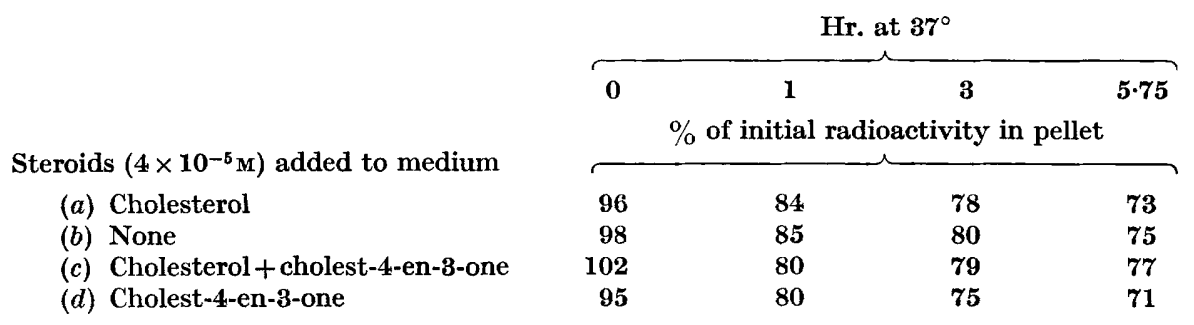

\section{DISCUSSION}

The results of the growth tests were qualitatively the same for the two strains examined; there were some quantitative differences. These are more likely to have been due to the differences in the lipid composition of media B1 and B2 than to differences in the sterol requirements of the two strains. The concentration of cholesterol required for growth of strain $\mathbf{v} 5$ was greater in medium B2 than in medium B1. Other experiments have shown that this requirement for higher 
concentrations of cholesterol by strain $\mathrm{v} 5$ in medium B 2 was related to the increased fatty acid concentration rather than to that of defatted bovine serum albumin. The concentration of cholesterol required for optimum growth of strain $\mathrm{v} 5$ in a medium of undefined composition decreased from $5 \times 10^{-5} \mathrm{M}$ to $10^{-5} \mathrm{M}$ when Fraction $\mathrm{C}$ was defatted with ethanol + ether mixture (Rodwell, 1956)-(defatted Fraction $\mathrm{C}$ was used in the work described in this paper). Under conditions where a higher cholesterol concentration was required, either lipid associations formed with other medium constituents might have rendered some cholesterol unavailable to the organism, or cholesterol may have had a protective function (as suggested earlier, Rodwell, 1956) as well as being required as an essential metabolite.

Since the series of steroids examined was limited, not many conclusions can be drawn which relate structure to activity. Cholestanol, and lathosterol (which has a double bond in the 7 rather than the 5 position) promoted growth; these sterols also had growth-inhibitory properties when tested in the more sensitive system (strain v 5 in medium B 1 containing a lower concentration of cholesterol). The introduction of a second double bond, as in 7-dehydrocholesterol, almost abolished growth-promoting activity and conferred potent growth-inhibitory properties. Cholestanone was almost inactive as a growth promoter or a growth inhibitor; but cholestenone and cholest-5-en-3-one were potent inhibitors of cholesterol-promoted growth. These results support the conclusion of Smith \& Lynn (1958) that the $3 \beta$-hydroxy group is essential for growth-promoting activity, and differ from those obtained by Butler \& Knight (1960), who found that cholestanone, cholest-1-en-3-one and cholestenone promoted the growth of Mycoplasma laidlawii (strains A and B). However, the function of steroids in the nutrition of $M$. laidlawii is not clear. Steroids do not seem to be an essential nutritional requirement for this species since they can be replaced for growth in a partly defined medium by bovine serum albumin (Butler \& Knight, 1960). It is possible that, with this species, steroids may function primarily in a protective capacity. On the other hand, Rothblat \& Smith (1961) showed that their strains which did not require sterol for growth incorporated cholesterol when supplied with it. Cholesterol esters were not formed under the growth conditions described in this paper; it is possible that they might be formed under other growth conditions. But they do not appear to be essential constituents of $M$. mycoides.

It is concluded that, with the strains of Mycoplasma examined, cholesterol is incorporated without chemical modification or combination. It would be difficult to exclude the possibility that this is the result of an irreversible, but unnecessary, adsorption. It seems more likely that cholesterol forms part of the structure of the lipid membrane system. Certain other steroids, structurally closely related to cholesterol, can also be incorporated unchanged, and fulfil the same function. In a recent paper Smith (1962) reported that cholestanol and ergosterol were incorporated by a Mycoplasma organism without transformation to other steroids. Certain other steroids inhibit growth, either by interfering with the incorporation of cholesterol, or by themselves being incorporated into a membrane which, as a consequence, cannot function properly.

I wish to thank Dr T. S. Gregory for correcting this manuscript. 


\section{REFERENCES}

Barton, D. H. R. \& Cox, J. D. (1948). The application of the method of molecular structure and action differences in steroids. Part IV. Optical anomalies. J. chem. Soc. p. 783.

Butler, M. \& Knight, B. C. J. G. (1960). Steroid growth requirements and steroid growth inhibitors of Mycoplasma. J. gen. Microbiol. 22, 483.

Edward, D. G. FF. \& Fitzgerald, W. A. (1951). Cholesterol in the growth of organisms of the pleuropneumonia group. J. gen. Microbiol. 5, 576 .

Fieser, L. F. (1953). Cholesterol and companions. VII. Steroid dibromides. J. Amer. chem. Soc. 75, 5421.

Folch, J., Lees, M. \& Sloane-Stanley, G. H. (1957). A simple method for the isolation and purification of total lipids from animal tissues. J. biol. Chem. 226, 497 .

Kabara, J. J. \& McLaughlin, J. 'T. (1961). A microdibromide procedure for purifying radioactive cholesterol. J. lipid Res. $2,283$.

Kodicek, E. \& Ashry, D. R. (1954). Paper chromatography of vitamin D and other sterols. Biochem. J. 57, xii.

LAws, L. (1956). A pleuropneumonia-like organism causing peritonitis in goats. Aust. vet. J. $32,326$.

Lynn, R. J. \& Smith, P. F. (1960). Chemical composition of PPLO. Ann. N.Y. Acad. Sci. 79, 493.

Martin, R. P. (1957). Reversed phase paper chromatography and detection of steroids of the cholesterol class. Biochim. biophys. Acta, 25, 408.

Martin, R. P. \& Bush, I. E. (1955). Application of a reversed phase system for separation of the less polar steroids on paper. Fed. Proc. 14, 252.

Mrchalec, C. \& StraseK, J. (1960). A new paper chromatographic technique for the separation of cholesterol and cholesteryl esters. J. Chromatog. 4, 254.

Morowitz, H. J., Tourtellotte, M. E., Guild, W. R., Castro, Eisisea, Woess, C. \& Cleverdon, R. C. (1962). 'The chemical composition and submicroscopic morphology of Mycoplasma gallisepticum Avian PPLO 5969. J. molec. Biol. 4, 93.

Page, I. H. \& Rudy, H. (1930). Ưber die Fettsäureester des Cholesterins. Biochem. Z. $220,304$.

Peereboom, J. W., Coprus, J. W. \& Roos, J. B. (1960). Fette, Seifen, Ausstrichmittel. 62, 91. Cited in J. Chromatog. (1961), 5, D15.

Rodwell, A. W. (1956). The role of serum in the nutrition of Asterococcus mycoides. Aust. J. biol. Sci. 9, 105.

Rodwell, A. W. (1960). Nutrition and metabolism of Mycoplasma mycoides var. mycoides. Ann. N.Y. Acad. Sci. 79, 499.

Rodwell, A. W. \& Аввот, A. (1961). The function of glycerol, cholesterol and long-chain fatty acids in the nutrition of Mycoplasma mycoides. J. gen. Microbiol. 25, 201.

Rothblat, G. H. \& Sмith, P. F. (1961). Non-saponifiable lipids of representative PPLO. J. Bact. 82, 479.

Sмiтн, P. F. (1959). Cholesterol esterase activity of pleuropneumonia-like organisms. J. Bact. 77, 682 .

Sмiтн, P. F. (1960). Nutritional requirements of PPLO and their relation to metabolic function. Ann. N.Y. Acad. Sci. 79, 508.

Smrth, P. F. (1962). Fate of ergosterol and cholestanol in pleuropneumonia-like organisms. J. Bact. 84, 534 .

Smith, P. F. \& Lynn, R. J. (1958). Lipid requirements for the growth of pleuropneumonialike organisms. J. Bact. 76, 264.

Sperry, W. M. \& Webb, M. (1950). A revision of the Schoenheimer-Sperry method for cholesterol determination. J. biol. Chem. 187, 97.

Swell, L. \& Treadwell, C. R. (1955). Cholesterol esterases. VI. Relative specificity and activity of pancreatic cholesterol esterase. J. biol. Chem. 212, 141.

Turner, A. W., Campbell, A. D. \& Dick, A. T. (1935). Recent work on pleuropneumonia Contagiosa boum in North Queensland. Aust. vet. J. 11, 63.

Vahouny, G. V., Mayer, R. M., Roe, J. H. \& Treadwell, C. R. (1960). Determination of $3 \beta$-hydroxy sterols with anthrone reagent. Arch. Biochem. Biophys. 86, 210. 